\title{
REGISTRO Y DIBUJOS DE PIEZAS ARQUEOLÓGICAS DEL MUSEO REGIONAL Y ARQUEÓLOGICO “RODOLFO BRAVO", CAFAYATE, PROVINCIA DE SALTA, ARGENTINA
}

\author{
Diana Sandra Tamburini ${ }^{1}$
}

En este anexo se dan a conocer el registro y dibujos de 20 ejemplares que forman parte del Museo Regional y Arqueológico "Rodolfo Bravo", fundado en 1935 en la localidad de Animaná y trasladado en 1943 a la ciudad de Cafayate, Provincia de Salta, Argentina (Figura 1).
El museo contiene numerosas y diversas piezas arqueológicas de los Valles Calchaquies. Estas colecciones fueron reunidas personalmente durante más de 60 años por el Profesor Rodolfo I. Bravo, quien realizó investigaciones arqueológicas en la región en un radio de 30 kilómetros

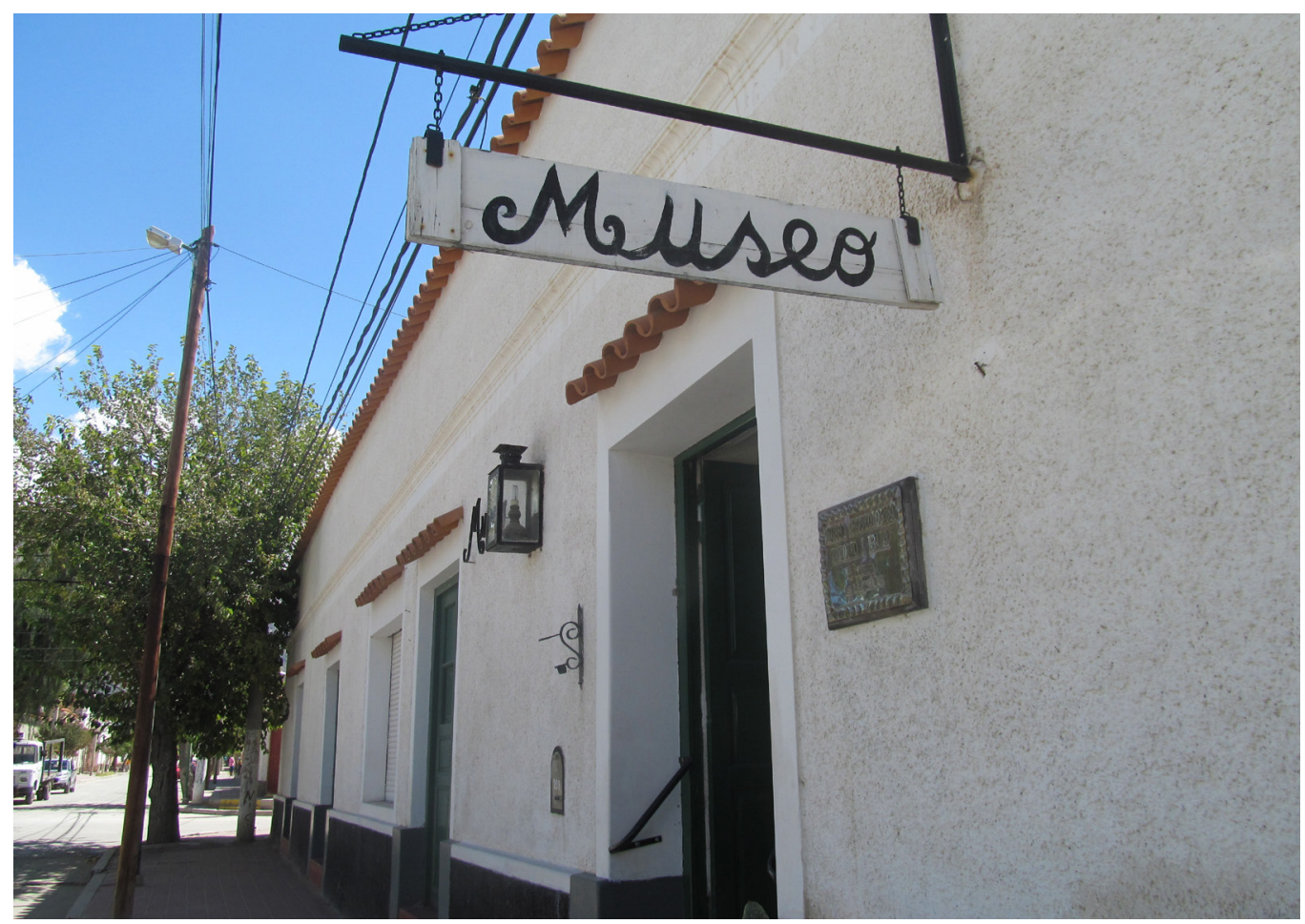

Figura 1. Museo Regional y Arqueológico “Rodolfo Bravo” Cafayate, Salta. (Foto Diana S. Tamburini, 2018).

1 CEAR - Departamento de Arqueología, Escuela de Antropología, Facultad de Humanidades y Artes. Universidad Nacional de Rosario. dianatamburini@hotmail.com 


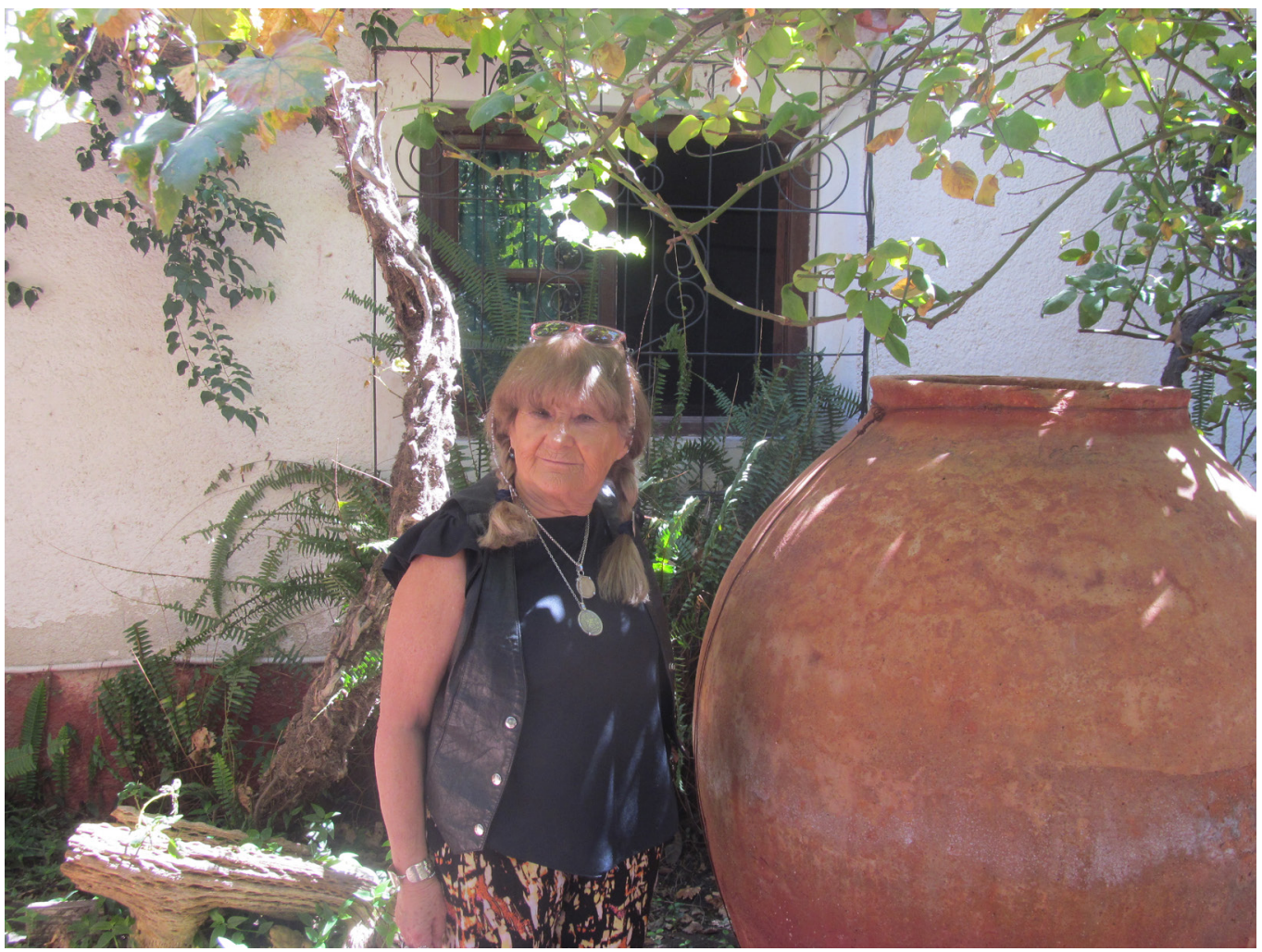

Figura 2. Prof. Helga H. Mazzoni en el patio de la vivienda familiar y donde también funciona el Museo (Foto Diana S. Tamburini, 2018)

de Cafayate. Bravo dedicó 66 años de su vida a reunir, clasificar y restaurar las numerosas piezas arqueológicas de su colección (Helga Mazzoni, comunicación personal, 2018). Desde 1991, el museo es mantenido y dirigido por su viuda, Helga H. Mazzoni (Figura 2), junto a su hijo Maximiliano Bravo.

El registro y dibujo de las 20 piezas arqueológicas que aquí se presenta fue realizado en 1961, por las investigadoras María Teresa Carrara (Figura 3) junto a Griselda Monti y Nelly Magnano, en el marco de las investigaciones que se llevaron adelante entre los años 1961 y 1964 en los alrede- dores de Cafayate (Salta) en el sitio Chimpa y también en quebradas que bajan hacia el Valle (Figura 4) (Tarragó y Scattolin 1999:2). Fue así como, en 1961, realizaron el relevamiento, registro y dibujos de 20 piezas arqueológicas de la denominada "Colección Bravo" de un total de más de 2.000 piezas que están resguardadas en el Museo (Helga Mazzoni, comunicación personal, 2018).

Este registro, ha permanecido inédito por más de 50 años y fue cedido personalmente por María Teresa Carrara en el año 2010, al Departamento de Arqueología de la Escuela de Antropología de la Facultad 


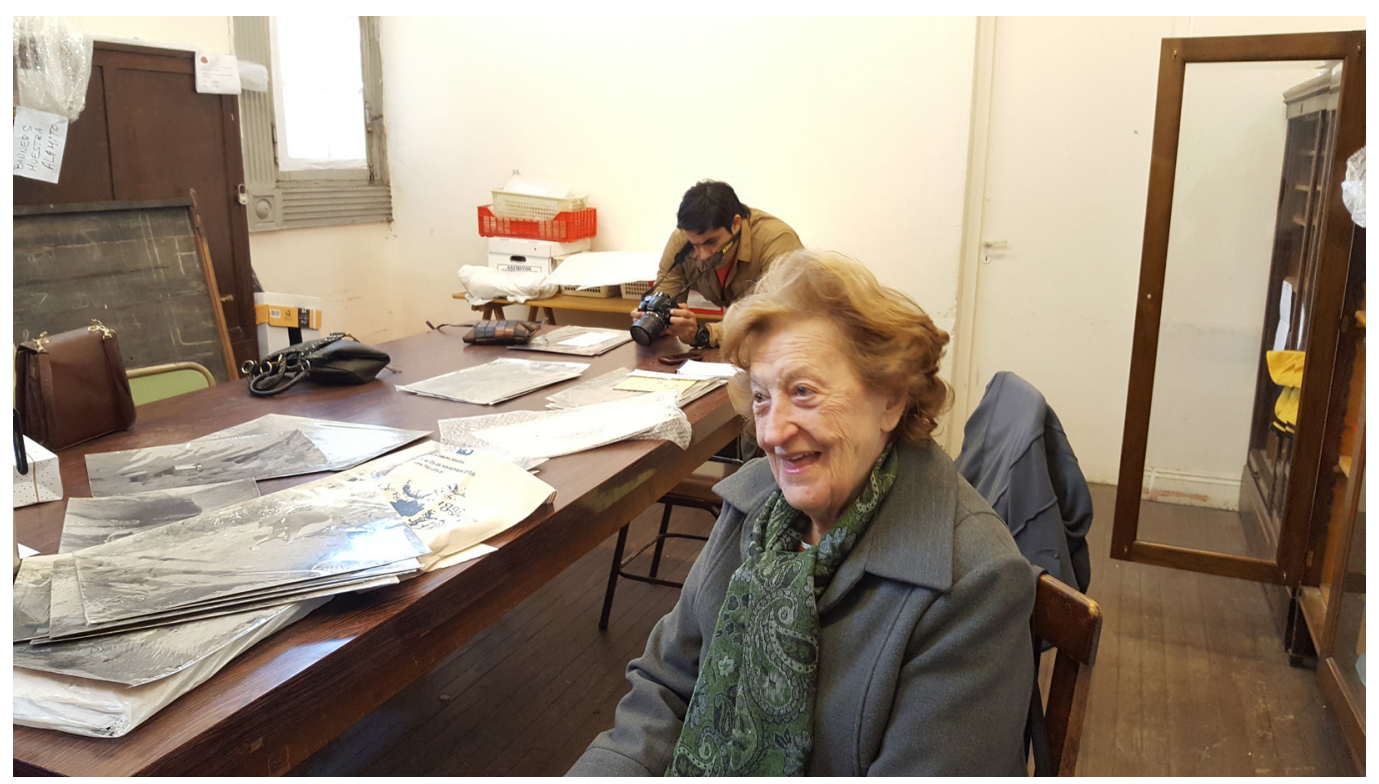

Figura 3: Prof. María Teresa Carrara en las $V^{\circ}$ Jornadas Rosarina de Arqueología, 2018 (Foto Diana S. Tamburini, 2018)

de Humanidades y Artes, Universidad $\mathrm{Na}$ cional de Rosario. Los dibujos originales fueron realizados a pincel con tinta china diluida en agua y carbonilla, no tienen escala y las medidas están detalladas en la descripción mecanografiada por las autoras. Sólo ha sido citado en dos ocasiones como manuscrito por Scattolin (2003, 2006a), publicándose algunos de sus dibujos en Tarragó y Scattolin (1999).

La gran mayoría de las piezas descriptas en este anexo proceden de sitios paradigmáticos para la ocupación humana prehispánica. Las autoras han seleccionado 10 piezas procedentes de Chuscha, 6 piezas procedentes de San Antonio y 4 piezas procedentes de El Divisadero.

Dado que uno de los mayores desafios que presentan los investigadores del Noroeste Argentino es la escasez de material de referencia para comparar los conjuntos de tiestos con piezas completas, creemos que este es un pequeño aporte para acceder a parte de las colecciones pertenecientes al Período Formativo (600 a.C.-900 d.C.) del Noroeste Argentino (sensu Núñez Regueiro 1974). 


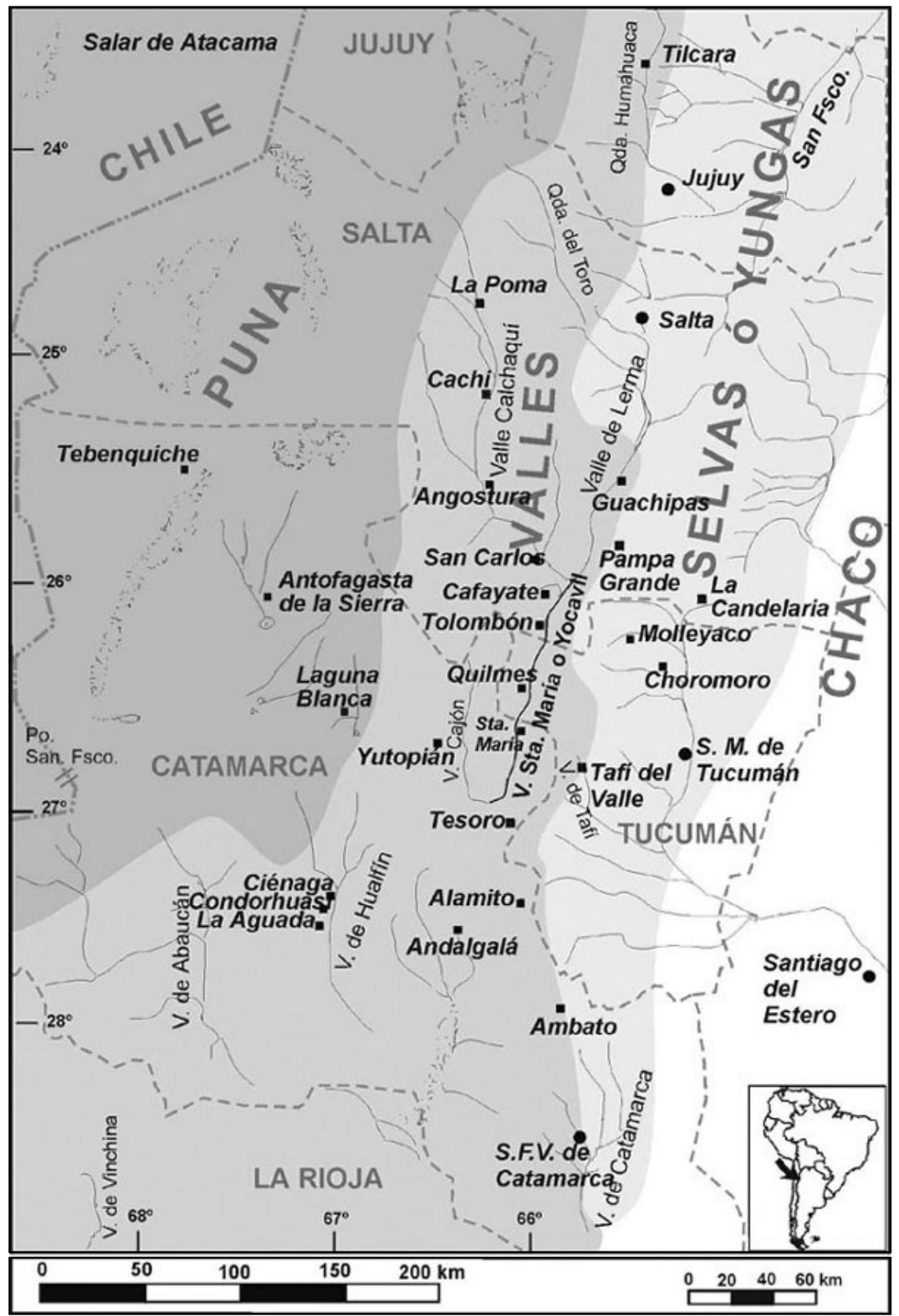

Figura 4. El valle de Santa María y alrededores (tomado de Scattolin 2006b). 
Bibliografia

NUÑEZ REGUEIRO, V. 1974. Conceptos instrumentales y marco teórico en relación al análisis del desarrollo cultural del Noroeste Argentino. Revista del Instituto de Antropología 5:169190.

SCATTOLIN, M. C. 2003. Los ancestros de calchaquí: una visión de la Colección Zavaleta. Cuadernos de la Facultad de Humanidades y Ciencias Sociales 20:51-79.

SCATTOLIN, M. C. 2006a. Contornos y confines del universo iconográfico precalchaquí del valle de Santa María. Estudios Atacameños 32:119-139.

SCATTOLIN, M.C. 2006b. Categoremas indigenas y designaciones arqueológicas en el Noroeste Argentino prehispánico. Chungara 38(2):181-192.

TARRAGO, M. y M. C. SCATTOLIN. 1999. La problemática del Período Formativo en el valle de Santa María. Actas del XII Congreso Nacional de Arqueología Argentina, Tomo 1, pp. 142-153. La Plata. 
